


\section{El café de Colombia. \\ Un modelo de diferenciación de producto, posicionamiento de marca y valor agregado}

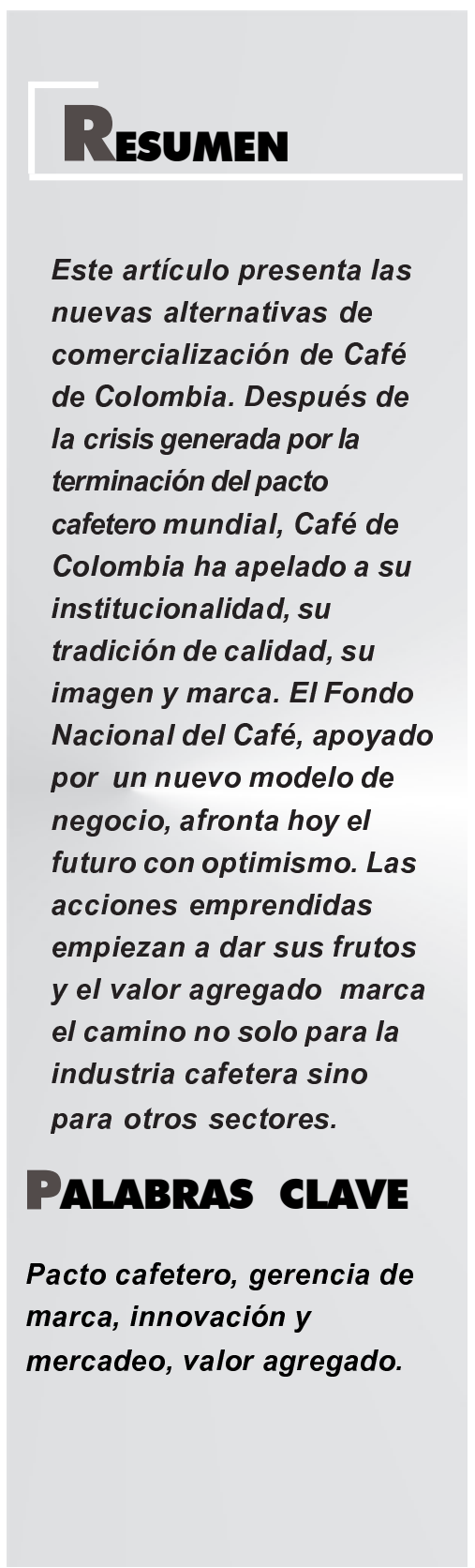

Por:

Miguel Samir Kiuhan

Francisco Javier Matíz Gabriel Pinzón

Román Rodríguez M. Alvaro Rojas ${ }^{1}$

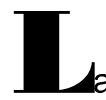

a vida de Colombia está estrechamente relacionada con la producción y comercialización del café. Por más de cien años el país ha recibido de esta industria los recursos para buena parte de su desarrollo social y su crecimiento económico. Su mercado ha transcurrido por períodos de prosperidad que marcaron un camino ligado a ingresos importantes del comercio internacional del grano para un gran número de cultivadores y mano de obra vinculada con la industria.

La diplomacia cafetera colombiana logró acuerdos duraderos entre productores y consumidores que garantizaron épocas de estabilidad y de orden de oferta y demanda, no obstante la volatilidad que es propia de este producto.

\footnotetext{
1 Miguel Samir Kiuhan. Director Gerencia de Mercadeo de la Escuela de Administración de Negocios.

Francisco Javier Matiz B. Profesional en Comercio Internacional con Especialización en Sicología del Consumidor y Candidato a la Maestría de Gestión de Organizaciones de la UQAC Coordinador del Programa Emprendedor de la Escuela de Administración de Negocios EAN

Gabriel Pinzón. Director Financiero Universidad Colegio Mayor de Cundinamarca.

Román Rodríguez M. Profesional en Ingeniería Eléctrica con Especialización en Mercadeo y Candidato a la Maestría de Gestión de Organizaciones de la UQAC.; actualmente es Consultor Senior en Franklin Covey Colombia y docente en programas de postgrado en la EAN.

Álvaro Rojas. Docente Facultad de Administración de Empresas-EAN
} 
A finales del siglo pasado la liberación del mercado mundial del café sumió a los países productores en la más profunda de sus crisis, ocasionando disminución de ingresos y deterioro de las condiciones sociales y económicas en todas las zonas productoras.

Colombia no escapó a esos efectos; sin embargo, su institucionalidad, su tradición de calidad, su imagen y marca, el Fondo Nacional del Café, apoyados por un nuevo modelo de negocio, permiten hoy ver el futuro con optimismo. Las acciones emprendidas empiezan a dar sus frutos y el valor agregado marca el camino no solo para la industria cafetera sino para otros sectores.

En Colombia el café inició su cultivo comercial hacia 1870, época en que se realizaron siembras crecientes del grano, se incorporaron amplias zonas a su producción y se ocupó de manera masiva mano de obra rural. En este proceso tuvo cabida un gran número de cultivos de pequeña escala, característica que ha perdurado a través de los años y que vincula amplios sectores de la población rural representados en pequeños propietarios. (Ocampo, 1989) Paralelamente se experimentó una sostenida expansión del sector externo de la economía colombiana. El país salió de unas infructuosas experiencias en productos como la quina y el tabaco y concentró buena parte de su esfuerzo en el café.

Desde entonces el café ha generado importantes ingresos al país, ha llegado a representar en algunos años hasta un $80 \%$ de las exportaciones. Ya en 1920 se exportaron más de dos millones de sacos de café por valor superior a los cien millones de dólares (Silva, 2003). Igualmente los recursos de la industria han sido instrumento fundamental para el desarrollo de la infraestructura de las zonas cafeteras y del país en general. La industria, la banca y otros sectores de la economía se desarrollaron a instancias del café. (Chalarca, 1998).

En la actualidad este producto tiene un papel menos destacado en los agregados económicos, pero continúa siendo el mayor generador neto de divisas. Es el tercer renglón de las exportaciones con productos que llegan a 80 destinos en todo el mundo y se destaca muy especialmente por la red social que conforma el sector cafetero en Colombia, que se ve reflejada en un clima de bienestar de la población de las zonas cultivadoras del grano, superior a otras regiones del país (Silva, 2003).

\section{A Bstract}

This paper explores new ways in merchandising for the Café de Colombia, a well consolidated trade mark world-wide. After the crisis caused by the breaking of the pact of the coffee producers, Café de Colombia has appealed to its key factors: quality, image, trade mark position. The Fondo Nacional del Café, supported by a new model of business, faces the future optimistically. Most of the measures and decisions on the way of added value show an improving symptom for the coffee industry and for its related sector.

\section{KEY wORDS}

Coffee agreement pact, trade management, innovations and marketing, added value 
Desde 1927 los cultivadores se encuentran agremiados en la Federación Nacional de Cafeteros, entidad privada creada por el segundo Congreso Cafetero Nacional, reunido en la ciudad de Medellín. La Federación es el centro de la actividad institucional cafetera. Portadora de la representación de los caficultores, la Federación ha concertado con el gobierno nacional la política cafetera y la creación y administración de los instrumentos creados para desarrollo y beneficio de la industria, entre ellos el más destacado es el Fondo Nacional del Café.

Una diferenciación especial de la caficultura colombiana es su institucionalidad y el conjunto de instrumentos con que se aplican las políticas del sector. A este conjunto se le llama frecuentemente modelo cafetero colombiano. Es muy diferente de otros esquemas aplicados en el concierto mundial de los países productores y ha perdurado exitosamente para bien de la caficultura en las épocas de prosperidad y para remontar los períodos adversos.

El centro del modelo colombiano es la Federación Nacional de Cafeteros, organización gremial privada cuyo objetivo principal es defender el ingreso de los caficultores. Es un esquema de participación democrática de los cultivadores cuya estructura representativa tiene en cuenta a todas las regiones productoras del grano. La Federación ha sido el medio por el cual se concilia la política para el manejo del café y la política macroeconómica (Pizano, 2001). El gobierno nacional y la representación gremial a través de la Federación han logrado un marco eficiente de concertación (Ocampo, 1997). La Federación actúa como exportador y su presencia en el mercado mundial se considera definitiva para preservar las ventajas de precio del café colombiano y la consistencia en la oferta ${ }^{2}$.

Con el ejercicio de este modelo Colombia ha logrado estructurar un sistema de producción, compra, almacenamiento, procesamiento, exportación y comercialización de su café. La garantía de compra de la cosecha, la estabilización del ingreso al productor y el estricto control de la calidad, fuente de la prima que reconoce el mercado al producto colombiano, apoyan directamente al caficultor. Colombia cuenta con un sofisticado sistema de mercadeo interno para garantizar la compra del café ofrecido a un precio justo. Los productores comúnmente reciben entre un 70 a $75 \%$ del precio FOB del café cuando venden su cosecha a través de este sistema (Banco Mundial, 2002). La Comisión de Ajuste de la Institucionalidad Cafetera, en su informe final, indicó al respecto: «El mecanismo más importante con que cuenta la institucionalidad cafetera para defender al productor es la garantía de compra. En el sentir de la Comisión la responsabilidad de ser el comprador de última instancia es un pilar irrenunciable y debe ser preservada aún a costa de sacrificar otros servicios y programas menos vitales $»^{3}$.

De otra parte el gremio cafetero ha ejecutado grandes inversiones en infraestructura física y social en todas las zonas productoras, se han creado empresas de interés para el sector, se realiza investigación a través de CENICAFÉ, se han utilizado recursos en promoción y publicidad que han dado excelente posición al producto y a su marca y se lleva el café a todos los destinos en el mundo.

\footnotetext{
${ }^{2}$ Comisión de Ajuste a la Institucionalidad Cafetera. Informe Final. 2002.

${ }^{3}$ Comisión de Ajuste a la Institucionalidad Cafetera. Informe Final. 2002.
} 
Estas realizaciones han sido financiadas gracias a que desde inicios de la actividad exportadora del grano los productores decidieron aportar recursos para programas de beneficio del mismo sector, captados por medio de gravámenes a las exportaciones. Estos recursos son administrados a través del principal instrumento de la industria: El Fondo Nacional del Café, creado en 1940. Es una cuenta del Tesoro Público administrada por la Federación de Cafeteros. Se concibió para acumular existencias en cumplimiento de compromisos del Acuerdo Interamericano de Cuotas de Café, con el tiempo se fueron adjudicando otros procesos que abarcan las actividades más importantes de la industria del café.
El modelo cafetero colombiano ha sido reconocido mundialmente e infructuosamente imitado por otros países productores. Diferentes investigadores han estudiado el origen, permanencia, coherencia y otras características particulares del éxito de este modelo, logrado por su institucionalidad y fundamentado en un amplio grupo de pequeños y medianos cultivadores que agremiados han participado en la formulación de su propio destino con visión de largo plazo. Colombia logró crear y afianzar un modelo cafetero auténtico, coherente y exitoso que debe llamar la atención para que otros sectores orienten sus esfuerzos colectivos.

\section{El café, la economía colombiana y el mercado internacional}

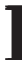
La evolución del sector cafetero colombiano puede observarse en el comportamiento de sus principales variables. El cuadro siguiente muestra por décadas cien años de este proceso. Las áreas dedicadas el cultivo, el número de fincas, las exportaciones y la participación en el PIB dan una idea clara del crecimiento y dimensiones que ha tomado la caficultura.

Principales indicadores de la caficultura colombiana 1900-2000 Promedios anuales por década

\begin{tabular}{|l|l|r|r|r|r|r|r|r|r|r|r|}
\hline Variables & Unidad & $\mathbf{1 9 0 0 - 0 9}$ & $\mathbf{1 0 - 1 9}$ & $\mathbf{2 0 - 2 9}$ & $\mathbf{3 0 - 3 9}$ & $\mathbf{4 0 - 4 9}$ & $\mathbf{5 0 - 5 9}$ & $\mathbf{6 0 - 6 9}$ & $\mathbf{7 0 - 7 9}$ & $\mathbf{8 0 - 8 9}$ & $\mathbf{9 0 - 0 0}$ \\
\hline Area con café & Miles Has. & & & 232 & 358 & & $\mathbf{7 7 7}$ & & 1070 & 1010 & 805 \\
\hline Fincas cafeteras & Número & & & 39110 & 140348 & & 234674 & & 302945 & 566230 & \\
\hline Exportación & Miles s/s 60 & 0,6 & 1,1 & 2,2 & 3,5 & 5,5 & 6,4 & 7,6 & 8,7 & 12,1 & 12,7 \\
\hline Principales mercados & & & & & & & & & & & \\
\hline Estados unidos & $\%$ & 72,0 & 91,2 & 93,4 & 81,7 & 93,9 & 84,2 & 56,4 & 37,5 & 21,5 & 24,6 \\
\hline Europa & $\%$ & 28,0 & 8,2 & 6,1 & 15,6 & 2,7 & 13,2 & 39,9 & 56,5 & 66,5 & 59,2 \\
\hline Japón & $\%$ & 0,0 & 0,1 & 0,0 & 0,0 & 0,0 & 0,2 & 1,1 & 2,6 & 6,0 & 9,9 \\
\hline Otros & $\$$ & 0,0 & 0,5 & 0,5 & 2,7 & 3,4 & 2,4 & 2,6 & 3,4 & 6,0 & 6,3 \\
\hline Valor de exportaciones & & & & & & & & & & & \\
\hline Totales & US\$Mills & 13,9 & 35,9 & 86.2 & 89,0 & 182,1 & 523,1 & 510,0 & 1709,6 & 4403,8 & 9644,2 \\
\hline Café & US\$Mill & 5,4 & 19,3 & 59,3 & 50,2 & 129,6 & 419,4 & 343,4 & 971,6 & 1854,3 & 1661,2 \\
\hline Participación del PIB & & & & & & & & & & & \\
\hline Agropecuario & $\%$ & & & & & & 9,7 & 7,3 & 5,6 & 5,6 & 4,4 \\
\hline Total & $\%$ & & & & & & 27,7 & 24,0 & 11,0 & 13,1 & 11,3 \\
\hline
\end{tabular}

Fuente: recopilación de diversas fuentes. 
Gráfica 1

Colombia, participación del café en el valor de las exportaciones totales. Porcentaje por décadas

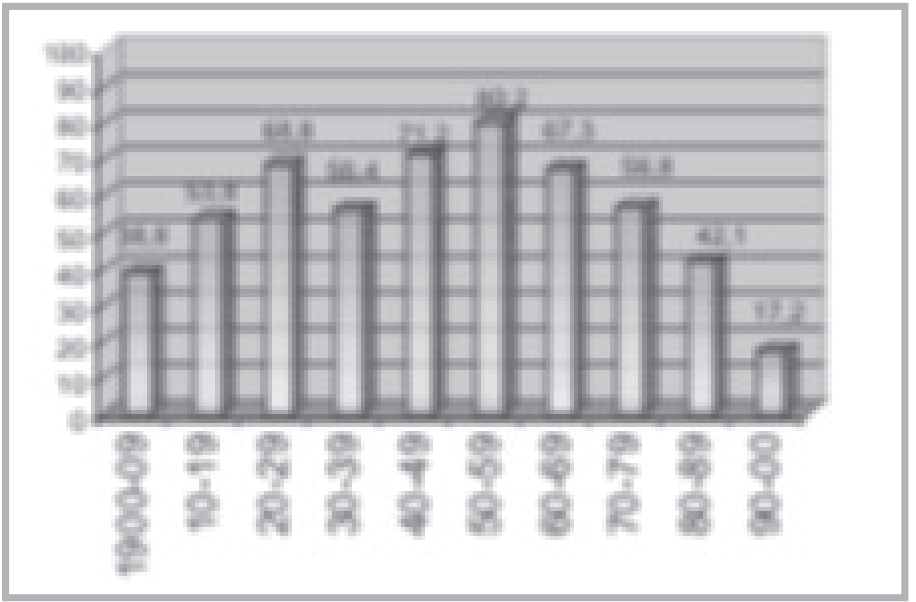

Fuente: Federación Nacional de Cafeteros

Gráfica 2

Colombia-evoución de la participación del café en el pib total y en el agropecuario-promedios anuales

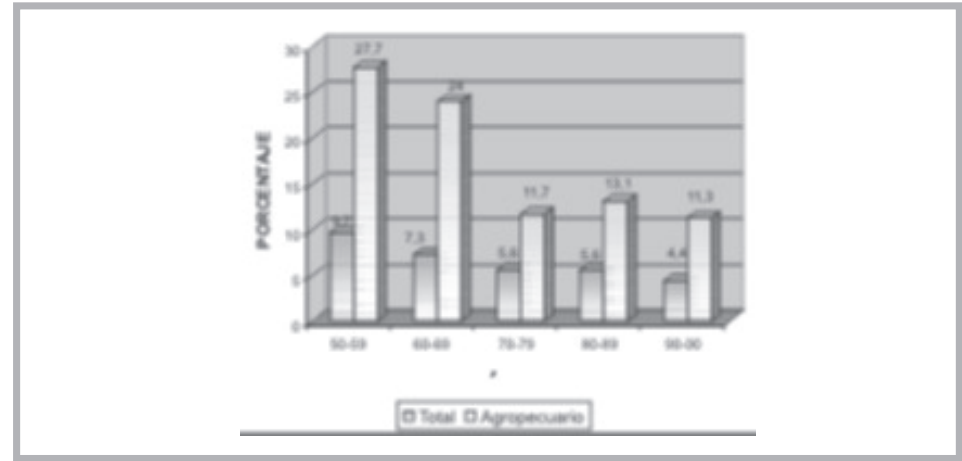

Fuente: Federación Nacional de Cafeteros

Gráfica 3

Valor real de la cosecha 1990-2001

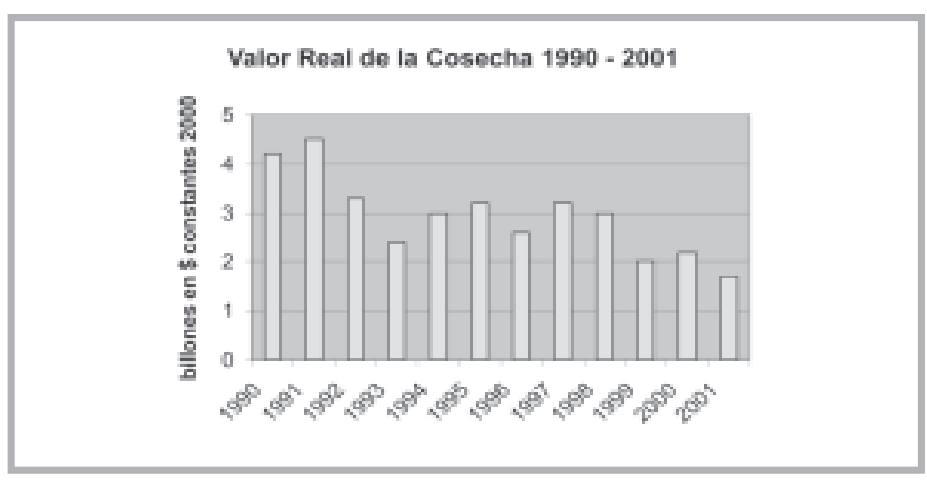

Fuente: Federación Nacional de Cafeteros 
En la actualidad, la producción y comercialización del café genera un millón de empleos y cuenta con 560.000 cultivadores en 590 municipios. Representa el $36 \%$ del empleo agrícola y genera más del $20 \%$ del PIB agrícola nacional. Continúa siendo una actividad de pequeños productores pues el $73,7 \%$ de las fincas tiene entre 0,1 y 5 hectáreas. Las inversiones que ha logrado la institucionalidad en la red social cafetera han permitido llevar energía eléctrica a 200.000 hogares, la construcción de 5.000 acueductos rurales, 2.500 puentes, 11.000 kilómetros de carreteras, 17.000 aulas, educación para 360.000 niños, 180 hospitales locales y 200 centros de salud, entre los principales conceptos de inversión. (Silva, 2003)

La depresión de los precios internacionales del grano, que siguieron a la ruptura de las cláusulas económicas del pacto internacional del café, propició una drástica disminución de los ingresos de los países productores, generando la crisis que acompañó la economía cafetera desde los últimos años del siglo XX hasta el inicio del presente. Colombia ha empezado a remontar esta crisis con base en su institucionalidad, un profundo replanteamiento de su industria y su modelo de comercialización.

El comportamiento de las exportaciones colombianas en los últimos 7 años cafeteros ha oscilado entre 9 y 11 millones de sacos de 60 kilogramos.

En los dos últimos años el mercado mundial tuvo un comportamiento positivo en sus precios como resultado de una disminución de la oferta mundial, en tanto que el consumo presentó una tendencia creciente. Para Colombia el aumento de las cotizaciones ha representado un repunte que pasó de un promedio de 77 centavos de dólar por libra en el año 2003/2004 a 114 centavos por libra en el 2004/2005. Para este último año las ventas de café colombiano fueron de 1557 millones de dólares que es la cifra más alta en los últimos siete años (Federación Nacional de Cafeteros de Colombia, 2005). No obstante, larevaluación del peso ha afectado lacompetitividad de las exportaciones colombianas. En efecto el año cafetero 2004/2005 representó menores ingresos para los caficultores por el orden de 295 mil millones de pesos frente a una hipótesis de devaluación del $4 \%$.

En la participación de la producción mundial se destaca un aumento deAsiafundamentalmente explicado por la incorporación de la oferta de Vietnam. Colombia, a diferencia de otros productores, resistió los efectos en la producción causados por la caída de los precios y ha logrado situar su producción entre 11 y 12 millones de sacos frente a la producción mundial que se estima en 110 millones de sacos. Brasil produjo en el 2004 cerca de 40 millones; por su parte Vietnam, cuya producción en el 2004 llegó a 15 millones de sacos, ha visto drásticamente reducido su volumen tras una fuerte sequía en las zonas de mayor producción y un aumento del costo de los insumos. En el 2005 cerró con un volumen cercano a 11 millones de sacos. (Federación Nacional de Cafeteros de Colombia, 2005)

Por su parte, el consumo del café en el mundo ha presentado una tendencia creciente en los últimos años. Para el año cafetero 2004/2005 se estima que fue de 115.1 millones de sacos mientras que un año atrás había sido de 111.8 millones, un incremento del $2.95 \%$. Esta tendencia se observó en el aumento del consumo en los países productores y en menor proporción en los países importadores. (Federación Nacional de Cafeteros de Colombia, 2005) El positivo cambio en la tendencia del consumo es una de las noticias más importantes en el mundo cafetero. 
El consumo en los Estados Unidos, uno de los principales mercados, también experimentó esta tendencia. Alemania se consolida como el tercer consumidor después de Estados Unidos y Brasil.

El consumo en Japón creció el 5,2\%, donde Colombia es el principal proveedor en términos de valor. Los mercados no tradicionales han crecido en proporciones importantes, se destaca China que en la última década ha aumentado el 39.3\%. (Federación Nacional de Cafeteros de Colombia, 2005)

El balance mundial ha cambiado su tendencia y el consumo ha superado a la producción en los últimos dos años. Esta es la causa central del repunte de precios. La gráfica siguiente presenta el balance oferta demanda en el período 1981 a 2005.

Gráfica 4

Balance mundial cafetero, en millones de sacos de $60 \mathrm{~kg}$

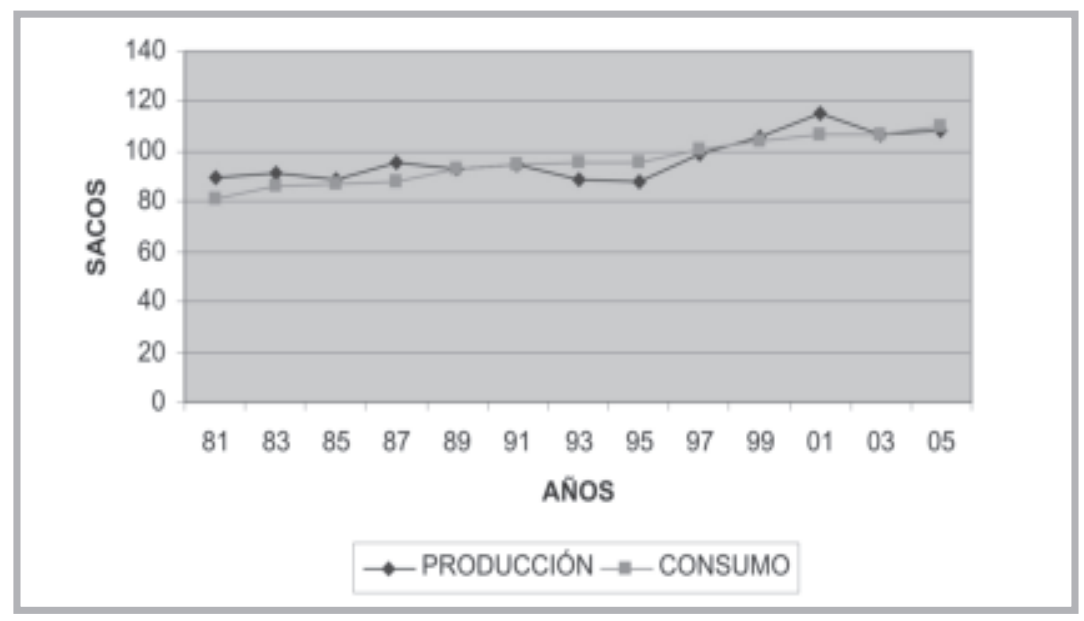

Fuente: Green Coffee Associations

\section{La crísis del café}

AÑO 1989: fin del pacto

Las causas de la crisis cafetera se remontan a 1989, época en la que las cláusulas económicas del pacto cafetero entre países consumidores y productores se desmontaron. El pacto tenía como finalidad principal la regulación de precios y el control del suministro del café. La caficultura colombiana era rentable y le permitía financiar instituciones e instrumentos como la Federación y el Fondo Nacional del Café, que cumplen importantes funciones en el contexto del comercio controlado y el fomento de la caficultura.

En el año 2001 se registró el precio real externo del café más bajo de la historia colombiana de los últimos 180 años. A diferencia de décadas anteriores, los impactos macroeconómicos no han tenido una magnitud tan grande. En la década del 50, las exportaciones cafeteras representaban el 9,7\% del PIB nacional; en el período 90-98 eran del 4,4\% (Pizano, 2001) y para el año 2001 , el aporte no alcanzaba el $1 \%$ del PIB. Esta pérdida de peso macroeconómico se 
explica en parte por la drástica caída de los precios internacionales del grano, pero también por el aumento de las exportaciones menores y de hidrocarburos. (Perfetti et al.)

A nivel internacional (salvo en Colombia y otras pocas excepciones) se desmontaron las instituciones que regulaban el comercio del café y éste quedó sometido a las fuerzas del libre mercado.

La principal causa de la caída de los precios es que el consumo no presentaba crecimientos como en épocas anteriores pero la producción mundial sí aumentaba, especialmente en los países asiáticos, donde Vietnam marcaba un liderazgo regional.

Los actores del mercado experimentaron un enorme cambio en su poder relativo ocasionado por la nueva realidad económica alrededor del café. Los productores y consumidores llevaban la peor parte; los bajos precios del grano se tradujeron en un aumento de los márgenes para los tostadores y comercializadores internacionales. La calidad también salió afectada y los consumidores habituales empezaron a abandonar el consumo regular del café sustituyéndolo por otras opciones.

En Colombia, el problema de precios tenía otros elementos característicos, por el costo que tienen las instituciones e instrumentos cafeteros para los productores.

Tradicionalmente el Fondo Nacional del Café, que es administrado por la Federación Nacional de Cafeteros ha prestado todo tipo de servicios de apoyo a los productores y realizado importantes inversiones sociales, pero estos programas, cuya calidad siempre ha sido reconocida, tienen un costo y parte del impacto negativo de la crisis de la caficultura se vio reflejada en la reducción de las inversiones en infraestructura social.

Para el año 1999, por cada libra de café exportado, 23 centavos de dólar se destinaban a pagar las inversiones del Fondo. En tiempos de bonanza los cafeteros pagaban de buen grado este aporte; sin embargo, para el año 2000 los cafeteros no se podían dar ese lujo lo que trajo importantes recortes en los programas financiados con recursos del Fondo Nacional del Café. (Revista Semana, 2002)

Pero los esfuerzos no fueron suficientes para equilibrar las finanzas. A los bajos precios externos se sumó la crisis de algunas de las inversiones del Fondo en otras entidades, tales como el Banco Cafetero y la Flota Mercante Grancolombiana. Ala postre, la operación del Fondo fue deficitaria.

\section{Cambio estructural}

Las cifras de LMC International, de Oxford, Inglaterra, una firma especializada en el análisis del mercado cafetero mundial, indicaban que a junio del año 2001 la producción mundial de café llegaba a 116 millones de sacos, mientras el consumo total era de 107 millones, para un exceso de oferta en este año de más de 9 millones de sacos. A esta situación, que por sí misma ya ejercía una presión hacia abajo en los precios, se sumó al acumulado que venía de los años anteriores, para llegar a un inventario mundial que creció de 27 a 55 millones de sacos, al incluir el inventario de los países productores. Para diciembre del 2002 la acumulación de inventarios llegaba a niveles insostenibles, estimados en 75 millones de sacos. (Revista Javeriana, 2003)

La experiencia de los caficultores a lo largo de un siglo de actividad les enseñó una solución elemental cuando bajaban los precios 
del café: esperar. Después de cada depresión de precios seguía una bonanza, y el problema básico del productor era el de tener paciencia. En ese momento histórico-iniciando la década del 2000- las cosas eran diferentes, pues el ciclo tradicional de precios estaba amenazado.

La entrada de Vietnam como productor fue el fenómeno más importante a nivel de la oferta de café. Este país, que en 1980 prácticamente no tenía caficultura, entró en una fase de rapidísima expansión. Para 1990, su producción era cercana al millón de sacos y en el año 2001, bordeaba los 14 millones de sacos y para dicha época ya era considerada como el segundo productor mundial, después de Brasil. Colombia, que tardó 78 años para recorrer dicho camino ( 1 millón de sacos en 1900 y 12,5 millones de sacos en 1978), había sido relegada al tercer lugar, con 10,6 millones de sacos. (Revista Dinero, 2001)

Brasil comenzó a cultivar hacia el norte del país, en Minas Gerais, zona donde no se presentan las tradicionales heladas de las áreas del sur (Paraná y Sao Paulo), ejecutando de esta manera un cambio estructural en su caficultura. India, por su parte, que históricamente vendía su producción a la Unión Soviética, también contribuyó al exceso de oferta en el mercado mundial. Las devaluaciones de Brasil e Indonesia llevaron a esos países a multiplicar su agresividad en el mercado exportador.

En cuanto a la demanda, también se generaron cambios importantes. El exceso de oferta no estaba en los suaves arábigos, como el producido por Colombia, sino en el café robusta; sin embargo, la tendencia del mercado arrastró también a los suaves. Los tostadores cambiaron sus criterios para las mezclas utilizando cada vez mayores porcentajes de robusta.
La consecuencia fue un cambio total en el mercado cafetero mundial y la mejor demostración es el hecho de que las heladas no generaron impactos importantes en Brasil. En el año 2000 hubo 3 heladas y se perdió el $80 \%$ de la cosecha de Paraná pero el precio internacional del café prácticamente no registró el hecho.

En términos generales, se destacan los siguientes factores como los principales causantes de la crisis cafetera de finales del siglo XX y principios del XXI y que ha afectado a Colombia (Pizano, 2001):

- La expansión cafetera a nivel de la producción, especialmente por parte de Vietnam.

- El aumento importante en la siembra de árboles por parte de la industria brasileña del café.

- El debilitamiento de las organizaciones cafeteras en la mayoría de los países productores.

- El cambio tecnológico que ha permitido mejorar el control de plagas y modificar la participación de los cafés suaves.

- El crecimiento lento del consumo.

- Los movimientos en las tasas de cambio y en especial la reevaluación del peso colombiano.

\section{Cooperación internacional}

Durante el año 2000 se pusieron en marcha programas de retención de excedentes, liderados por Brasil y Colombia, donde el objetivo era retener el $20 \%$ de las exportaciones para impedir la acumulación 
de los granos en manos de los países importadores. En los primeros doce meses se logró retirar del mercado un volumen de 4 millones de sacos pero dicho esfuerzo no pudo contener la tendencia a la baja del grano, en parte porque no se logró el concurso activo de la mayoría de los productores de Asia, África e incluso de América. Para el fin del año 2002, el desequilibrio causado por la acumulación de los inventarios llegaba a niveles insostenibles, del orden de 75 millones de sacos, equivalente a las dos terceras partes del consumo mundial.

Además, una tercera parte de dichos inventarios se encontraba en poder de los países consumidores, dificultando la respuesta de los precios externos ante los controles de la oferta acometidos por los países productores.

\section{Dimensión social de la crisis}

Al rededor de 125 millones de personas distribuidas por todo el mundo dependen de la actividad cafetera y de este total, 25 millones son agricultores en 50 países que trabajan en fincas de menos de 10 hectáreas.

En África, en países como Ruanda, Uganda y Etiopía, se acentuaron los niveles de pobreza ante la pérdida de ingresos por exportaciones superior al $40 \%$ en el 2002. En Centroamérica, para el mismo año, más de 600.000 personas perdieron sus puestos de trabajo a causa de la crisis cafetera. (Revista Javeriana, 2003)

Para Colombia el efecto de la crisis se demoró en llegar hasta los caficultores puesto que en 1989 se partía de una situación de buenos precios, un Fondo Nacional del Café solvente y una abundancia de inventarios. Las heladas del 94 en Brasil y la sequía del 97 en ese mismo país crearon breves episodios de alza de precios que permitieron a los colombianos mantener las mismas prácticas comerciales. Se perdió el sentido de urgencia que había impuesto la terminación del pacto cafetero. La situación social en las zonas cafeteras se deterioró rápidamente en los años 1998 a 2001. El desempleo aumentó, lo mismo que la deserción escolar y el número de hogares por debajo del nivel de pobreza. EI CRECE calculaba en ese entonces, que una caída de $23 \%$ en el valor de la producción cafetera frente al nivel de 1998, representaba la pérdida de 257.000 empleos.

Por su parte, el gremio cafetero se vio obligado a recortar inversiones en infraestructura social, en especial en educación y salud. Los estudios indican que la productividad de la caficultura está relacionada con la escolaridad de los trabajadores y la disponibilidad de servicios públicos.

La situación del Fondo Nacional de Café en 2001, se deterioró considerablemente. Los inventarios cayeron a cerca de 2 millones de sacos, el patrimonio del Fondo, que era de US\$1.600 millones en 1989, cuando desapareció el pacto de cuotas, bajó en 2001 a US $\$ 569$ millones.

Ante esta situación los cafeteros reconocieron que era conveniente redimensionar la caficultura colombiana, la cual debería reducirse en los años subsiguientes, con grandes efectos, principalmente en las cifras económicas y en la importancia del sector cafetero en ellas.

Con el apoyo gubernamental a la caficultura (AGC) se buscó aliviar la situación de los cafeteros. Su costo total fue de 350.000 millones de pesos para los años 2001 y 2002. Las medidas consistieron en apoyos directos al cultivador en la compra de sus cosechas, incentivos para la renovación de 140.000 
hectáreas cafeteras con el fin de aumentar la productividad y defenderse mejor en tiempos de precios bajos. De otro lado se recortaron los gastos institucionales con cargo al Fondo Nacional del Café.

En cuanto a las deudas de los productores, se abrieron dos programas: uno para refinanciar deudas vencidas hasta por 210.000 millones de pesos y otro para reestructurar deudas hasta por 90.000 millones de pesos, para aquellos caficultores que estaban al día pero que difícilmente tendrían capacidad de pago en los siguientes dos años.

Todas estas medidas contribuyeron a aliviar lasituación, pero no fueron definitivas. Lamagnitud de la crisis fue tal que era imposible salir de ella sin una drástica reconversión del sector cafetero y del modelo de comercialización, aprovechando la experiencia institucional. Pese a la excelente posición de marca del Café de Colombia y su imagen de calidad fue, necesario innovar para encontrar nuevos esquemas.

En el plano de cooperación, Colombia, junto con otros países productores, ha venido trabajando en Ilamar la atención de los implicados en el comercio internacional del grano acerca de la inequidad del negocio cafetero mundial y sus efectos en las poblaciones productoras. (Silva Gabriel,) Diversas instituciones apoyan esta iniciativa ante las comunidades económicas de los países consumidores. (Oxfam Internacional, 2002) Igualmente se busca el mejoramiento de la calidad del café en el mercado mundial. Se logró que la OIC estableciera la Resolución 407 que determina estándares de calidad, a los que se les busca una acogida universal para que sean punto de referencia para el mercado. (Silva Gabriel,)

\section{La comisión de ajuste de la institucionalidad cafetera}

Por mandato del Comité Nacional de Cafeteros, la Comisión de Ajuste de de la Institucionalidad Cafetera recibió el mandato para efectuar un análisis independiente de la situación cafetera con el ánimo de que efectuara recomendaciones y propuestas de políticas.

En el año 2002 se hace la presentación oficial del informe final de la Comisión de Ajuste de la Institucionalidad Cafetera, conocido bajo el título de: El café, capital social estratégico. Las consideraciones fundamentales sobre las que la Comisión desarrolló su tarea fueron:

- El mercado del café debe ser de nuevo un tema fundamental de la agenda mundial encaminándose hacia soluciones concertadas tanto políticas como económicas para hacer de la caficultora una actividad sostenible y equitativa.

- Colombia, en asocio con otros productores, debe tomar el liderazgo para luchar contra el ejercicio oligopólico y la "cartelización" de los tostadores.

- Considerando el comportamiento internacional de los precios, debe plantearse una nueva estrategia cafetera.

- Hay que preservar la garantía de compra, aunque esto implique el sacrificio de servicios y programas menos vitales.

- El precio interno debe fijarse bajo consideraciones de mercado y solo cuando se genere un riesgo estructural de viabilidad de la producción nacional se considerará el uso de precios de sustentación. 
- Hay que crear empresarios del café y no solamente cultivadores del grano.

- Hay que defender la marca del Café de Colombia en los mercados internacionales.

La Comisión planteó además una estrategia con tres componentes básicos para fortalecer la competitividad de la caficultura colombiana:
- Investigación y transferencia de tecnología.

- Política de calidad y diferenciación de mercado.

- Estrategia de marca y comercialización externa.

\section{El valor agregado como un nuevo modelo de negocio para la industria cafetera colombiana}

Acogiendo las observaciones y propuestas de la Comisión, la Federación Nacional de Cafeteros a partir del año 2002 inició un nuevo modelo de comercialización desarrollando productos de mayor valor agregado con el ánimo de posicionar la marca país y obtener mayores márgenes en la cadena de valor. Así se pretende además minimizar el riesgo que representa el depender de los ingresos provenientes de un mercado primario y por ende el impacto de la volatilidad de los mismos en los ingresos de los cultivadores.

Este modelo con diversificación y diferenciación se basa en la experiencia, la alta calidad del grano, en el posicionamiento de marca y el respaldo de la institucionalidad cafetera en Colombia. Según la Federación Nacional de Cafeteros de Colombia en su informe anual del año 2005, "Sin duda seguimos siendo muy relevantes y muy importantes en la logística y en la operación de café verde, y este sigue siendo el grueso de nuestro negocio, pero hoy en día tenemos presencia a lo largo y ancho de toda la cadena de valor. ¿Y Gracias a qué? A un patrimonio marcario, una propuesta de valor, un café de altísima calidad, y una capacidad institucional de innovar y generar el seguimiento requerido para que estos esfuerzos empresariales produzcan resultados". Esta afirmación es en sí misma un gran enunciado estratégico en el modelo comercial de Colombia, donde la estrategia de desarrollo y comercialización de productos con mayor valor agregado aún es un esfuerzo naciente y como se verá a lo largo del presente documento su participación en los ingresos cafeteros y en los volúmenes de exportación del sector aún no es lo suficientemente significativa.

\section{Las estrategias}

La diversificación de productos y por ende la minimización de riesgos es uno de los principales objetivos del nuevo modelo comercial cafetero. Como parte de las nuevas propuestas de valor agregado se han venido desarrollando los siguientes programas o acciones:

\section{Política Marcaria y Denominación de Origen}

El posicionamiento de marca ha sido desde hace ya varias décadas un esfuerzo significativo dentro de la labor de la Federación Nacional de Cafeteros de Colombia, desde la creación de la marca Café de Colombia y el icono de 
Juan Valdez hasta nuestra fecha, las inversiones en este rubro han sido significativas y con importantes resultados en el reconocimiento por parte de los consumidores; prueba de ello es la elección de Juan Valdez como el personaje publicitario del año 2005 en el marco de la semana de la publicidad.

Pero la política marcaria del Café de Colombia no está solo apoyada en esfuerzos publicitarios y de recordación; la realización de contratos de licencia de marca han sido acciones igualmente importantes no solo para el posicionamiento de la marca sino para los ingresos cafeteros. En el año 2005 los 102 contratos de licencia de marca que cobijan un total de 992 marcas de terceros una facturación cercana a los 1.640 millones de pesos.

Por otra parte se han adelantado acciones a nivel nacional como en el mercado europeo, para la consolidación de la denominación de orígen del café de Colombia. «Una denominación de orígen es un nombre o signo distintivo correspondiente a una indicación geográfica, utilizado para identificar productos que tienen un origen geográfico concreto y poseen cualidades y reputación derivadas específicamente de ese lugar de origen, ya sea éste un país, región o localidad". (Café de Colombia)

Contar con la denominación de origen tanto a nivel nacional como en el territorio europeo proporcionará un marco legal para la defensa y protección del café colombiano, convirtiéndose en un elemento diferenciador entre el origen colombiano y el café de otros orígenes.

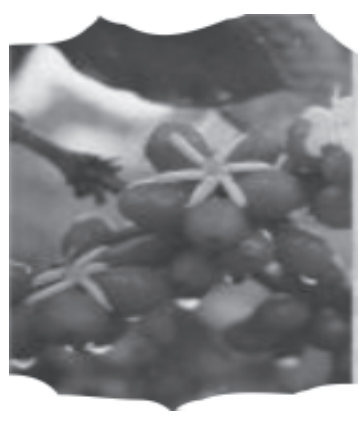

\section{Cafés especiales}

Los cafés especiales se definen como aquellos valorados por los consumidores por sus atributos consistentes, verificables y sostenibles y por los cuales están dispuestos a pagar precios superiores, que redunden en un mayor bienestar de los productores. Esta valorización del café es un diferencial importante frente a las fluctuaciones de los precios internacionales, ya que a pesar de que exista un alza de los precios del café estándar, el diferencial promedio se logra mantener.

En el informe $\mathrm{N}^{\circ} 24600-\mathrm{CO}$ del Banco Mundial de agosto de 2002, se definen estos cafés especiales como aquellos con características particulares de acuerdo con sus propiedades físicas, su apariencia sensorial y sus prácticas culturales de siembra, recolección, lavado y secado. Debido a que estos cafés mantienen una consistencia en sus características y tienen una oferta limitada.

Durante el año 2005 las exportaciones de este tipo de cafés estuvo alrededor de los 630.000 sacos (de $60 \mathrm{Kg}$.) cifra aún no muy significativa si se compara con el volumen de las exportaciones totales de café verde que para el año cafetero 2003 / 2004 estuvieron alrededor de nueve millones quinientos mil sacos según estadísticas de la Federación (Federación Nacional de Cafeteros de Colombia, 2005). Sin embargo el diferencial de venta promedio fue de 17.34 centavos de dólar por libra.

Es de destacar que los cafés diferenciados además de ofrecer una alternativa desde el punto de vista del precio para los caficultores, también favorecen la promoción de técnicas de producción sostenibles, convirtiéndose en una opción importante para los problemas de cosecha y postcosecha de los cultivadores. 


\section{Cafés liofilizados}

El café liofilizado de Colombia lo produce la Federación Nacional de Cafeteros, en las instalaciones localizadas en el municipio de Chinchiná. Esta fábrica es una de las más grandes y modernas del mundo y es la única planta de liofilización existente en Colombia. Dentro de los productos desarrollados por esta fabrica se encuentran el extracto concentrado de café, el café tostado, el café tostado y molido y el café liofilizado (descafeinado, aromatizado, saborizado), cuyos principales mercados son: Japón, Reino Unido, República Checa, Rusia, Alemania, Estados Unidos, Canadá, Corea del Sur, Dinamarca, Francia, Holanda, Italia, Polonia, Singapur, Suecia, Suiza, Australia, Israel, México, Ecuador, España y Colombia.

De acuerdo con el informe anual de la Federación Nacional de Cafeteros de Colombia en el año 2005 la producción de café liofilizado estuvo por el orden de las 7.200 toneladas de las cuales 6.750 se destinaron a mercados de exportación, lo que representó un incremento del $12 \%$ frente a la cifras del año 2004 generando ingresos del orden de los US\$ 62 millones y utilidades estimadas de US\$ 19 millones, lo anterior con la utilización del $92 \%$ de la capacidad instalada de la fábrica de Chinchiná.

En la actualidad la comercialización de los productos de café liofilizado se realiza a través de la marca Café Buendía y así como el desarrollo de marcas propias a grandes superficies. Esta estrategia se ha utilizado para incursionar en cadenas de gran importancia como WalMart, Target, Food For Less en los Estados Unidos y México, Sams en Canadá y Carrefour en Francia.

\section{Tiendas Juan Valdez}

Una de las más notables acciones de la Federación en el camino de desarrollar proyectos de valor agregado ha sido el establecimiento de las Tiendas Juan Valdez, una propuesta en la que se mezcla el icono publicitario del sector cafetero en Colombia y la posibilidad de probar una gran variedad de bebidas a base del café $100 \%$ colombiano.

En la actualidad la operación de las Tiendas se puede abordar desde su cobertura a nivel nacional con más de 21 puntos de operación en diversos centros comerciales, aeropuertos, teatros y puntos estratégicos de las principales ciudades colombianas, y en los mercados internacionales con 3 Tiendas en el mercado estadounidense.

De acuerdo con los reportes de la Federación, "al cierre de septiembre de 2005 las ventas promedio mensuales de las Tiendas Juan Valdez en Colombia alcanzaron la cifra de 1.000 millones de pesos, con el registro de un número de facturas promedio mensual de 120 mil", cifras en verdad significativas para una propuesta comercial con una presencia relativamente nueva en el mercado colombiano.

De igual forma las Tiendas se han venido convirtiendo en importantes clientes para el Fondo Nacional del Café. En el año 2005 compraron más de 240 toneladas de café verde con un sobre precio promedio del $20 \%$, siendo una nueva alternativa para la comercialización de productos del Programa de Cafés Especiales.

Dentro de las proyecciones se tiene como propósito una agresiva estrategia de crecimiento para los próximos cinco años alrededor de 100 tiendas Juan Valdez en Estados Unidos, ubicadas estratégicamente en pocos centros urbanos, y entre 30 y 50 
tiendas en otros, 3 a 5 países. Igualmente en el mercado nacional llegar a un ritmo de crecimiento que permita abrir una tienda por mes, hasta alcanzar las 60 tiendas en Colombia. (El Colombiano)

\section{Pods}

Los pods son un desarrollo de producto adicional que busca llegar directamente al consumidor final, es la propuesta para llevar el café colombiano del árbol a la tasa de los consumidores internacionales; la propuesta consiste en almohadillas de café para la preparación taza por taza, comercializadas a través de canales tales como los almacenes Target y las Tiendas Juan Valdez, principalmente en el mercado estadounidense.

Bajo esta línea en el año cafetero 2004-2005, se exportaron más de 13 millones de unidades, lo que representa un total de 2.300 sacos de café verde que representaron más de un millón y medio de dólares.

\section{Extractos de café}

Finalmente encontramos la línea de extractos de café. Esta línea de producto funciona a través de máquinas dispensadoras y en la actualidad tiene presencia principalmente en los Estados Unidos con 237 unidades, así como en Canadá y el Caribe con 28 y 22 unidades respectivamente. Parael presenteaño seespera ampliarla cobertura y consolidar este producto con la instalación de 675 nuevas máquinas.

\section{Los impactos}

La estrategia de desarrollo de productos de valor agregado aún está iniciando su proceso de implementación aunque con resultados importantes. La búsqueda de participación directa en los diferentes eslabones de la cadena productiva del café aún no representa un porcentaje importante dentro de la producción total de grano que para el año cafetero 2004 / 2005 alcanzó los 11,9 millones de sacos de los cuales más del $92 \%$ se destinó a los mercados internacionales, tal como se puede observar en el siguiente cuadro.

Tabla 1

Valor del café en millones de sacos de $60 \mathrm{~kg}$. Años cafeteros 1998-2205

\begin{tabular}{|l|r|r|r|r|r|r|r|}
\hline & \multicolumn{7}{|c|}{ Años } \\
\cline { 2 - 8 } & $98 / 99$ & $99 / 00$ & $00 / 01$ & $01 / 02$ & $02 / 03$ & $03 / 04$ & $04 / 05$ \\
\hline \multirow{2}{*}{ Producción } & 10,9 & 9,5 & 10,5 & 12 & 11,7 & 11,1 & 11,9 \\
\hline Exportaciones & 10,3 & 9,1 & 9,5 & 10,6 & 10,5 & 10,2 & 11 \\
\hline Consumo interno & 1,5 & 1,5 & 1,4 & 1,3 & 1,2 & 1,2 & 1,2 \\
\hline
\end{tabular}

Fuente: FNCC

Sin embargo la participación de los productos de valor agregado dentro del renglón exportador no es una cifra despreciable; en cuanto a cifras de volumen de exportaciones, productos tales como el café soluble, los extractos de café y los cafés tostados y molidos alcanzan a ser más de 600 mil sacos para el año cafetero 2003-2004. 
Tabla 2

Exportaciones colombianas por tipos de café. Años cafeteros 1998/99-2003/04

\begin{tabular}{|l|r|r|r|r|r|}
\hline \multirow{2}{*}{$\begin{array}{c}\text { Años } \\
\text { Cafeteros }\end{array}$} & \multicolumn{5}{|c|}{} \\
\cline { 2 - 6 } & Verde & Soluble & Extracto & Otros $^{*}$ & Total \\
\hline $1998 / 99$ & 9742 & 482 & 40 & 50 & 10324 \\
$1999 / 00$ & 8423 & 8423 & 32 & 15 & 9066 \\
$2000 / 01$ & 8841 & 8841 & 34 & 4 & 9473 \\
$2001 / 02$ & 10003 & 10003 & 27 & 6 & 10629 \\
$2002 / 03$ & 9907 & 9907 & 19 & 9 & 10480 \\
$2003 / 04^{* *}$ & 9543 & 9543 & 24 & 15 & 10155 \\
\hline
\end{tabular}

Fuente: FNCC

*Tostado y molido

Miles de sacos de $60 \mathrm{Kgs}$

Tal como se puede observar en los siguientes gráficos el peso de los productos de valor agregado dentro de la producción total cafetera aún no sobrepasa el $10 \%$; se podría determinar este rango de años (1999-2005) como una primera etapa del proceso de generación de productos de valor agregado y su internacionalización. Como se ha mencionado anteriormente, esto ha sido posible gracias a un decidido esfuerzo de investigación y desarrollo, así como al aprovechamiento de las inversiones en posicionamiento de marca país que ha adelantado el gremio durante más de 50años.
El hecho de que nuevos productos y esquemas de diferenciación en tan solo un quinquenio Ileguen a pesar el $6 \%$ del volumen de las exportaciones de café en un país donde este sector es uno de los más dinámicos dentro del comercio internacional, es de por sí un logro importante. Esto es más relevante si se observa cómo el café llega a tener el mismo peso relativo en la balanza comercial $(1320 \mathrm{mll}$ Usd) que el conjunto de productos exportados por el sector agrícola (1598 mll Usd), de acuerdo con cifras publicadas por el DANE para el periodo enero - noviembre del año 2005.

Gráfico 5

Exportaciones de café

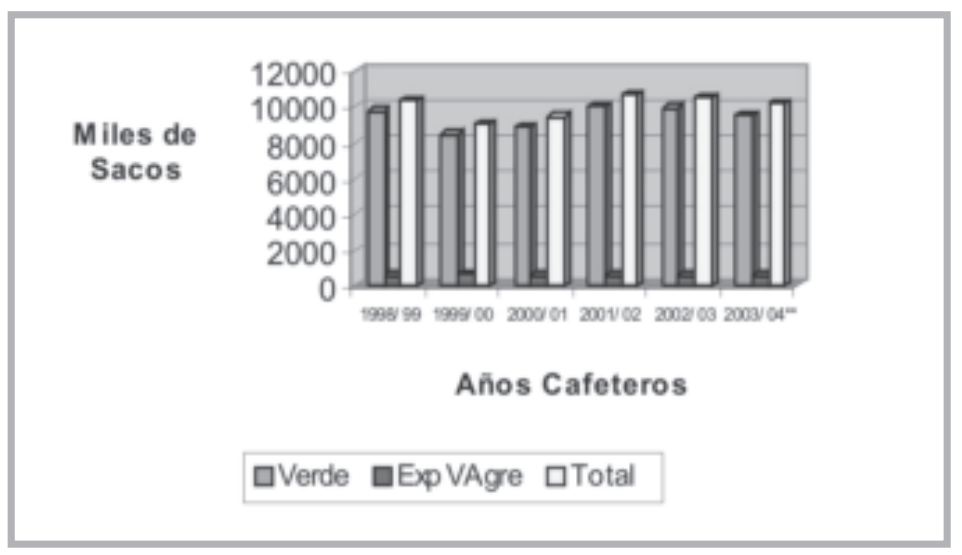


Gráfico 6

Exportaciones de café 1998-2004, en sacos de $60 \mathrm{~kg}$.

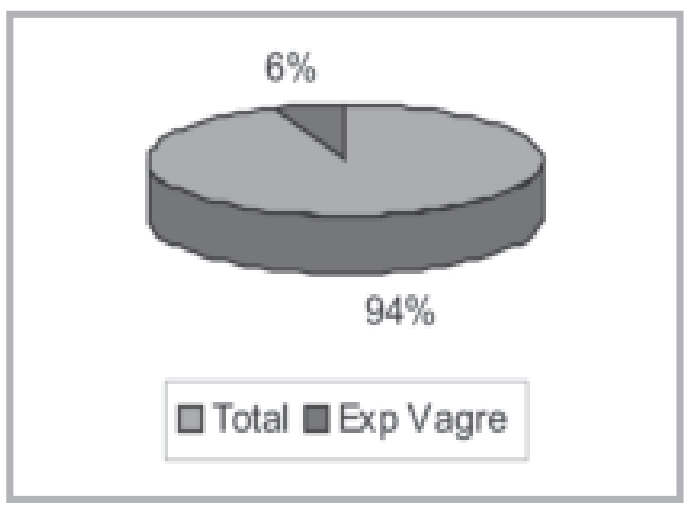

Aunque el verdadero impacto de estos esfuerzos por su misma concepción no está en la participación dentro del volumen total bien sea de las exportaciones o de la producción anual cafetera, sus principales resultados se encuentran en el valor adicional que puede generarse a través de la comercialización y producción de estos nuevos bienes, aspecto de gran importancia a la hora de analizar la variación de los precios internacionales del grano y la elasticidad de la demanda del mismo.

Desde este punto de vista y como se puede observar en el siguiente gráfico, la variación del valor adicional creado por los productos de valor agregado ha presentado un crecimiento significativo con incrementos en los últimos cuatro años de más del $210 \%$ y para el año 2005 de un $30 \%$.

Gráfico 7

Valor adicional creado en miles de millones de pesos

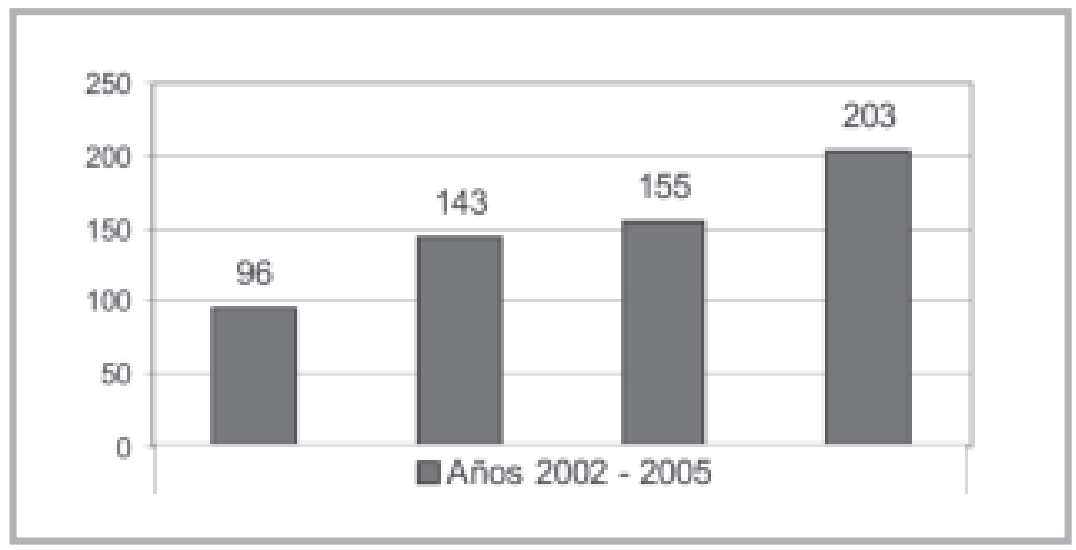

Es evidente que la estrategia de productos de valor agregado se perfila como el principal renglón agroindustrial colombiano, con una penetración decidida y agresiva en importantes canales de comercialización internacional, asícomo a través de la creación de canales propios de diferenciación en la mente de los consumidores globales.

Se puede en un futuro cercano prever una fuerte consolidación de los productos de valor agregado 
dentro del negocio cafetero en Colombia. El fortalecimiento de Procafecol, el apoyo de compañías de valor agregado y la colocación de sus acciones en manos de los caficultores del país, son una muy buena señal para la internacionalización de las nuevas líneas de producto. En los próximos años se ampliará la capacidad instalada de la planta de Chinchiná y se espera abrir un número importante de Tiendas Juan Valdez en los mercados estadounidense, europeo y asiático que permita convertirla en la segunda cadena del ramo.
Se espera que para el año 2015 este tipo de productos utilizarán un $40 \%$ de la producción nacional de grano, meta ambiciosa y significativa que convertiría el nuevo esquema comercial cafetero en un modelo no solo para otros sectores agrícolas en Colombia sino para muchas industrias. Es una lección de cómo la diferenciación, la alta calidad y el valor agregado hacia el consumidor son la mejor manera de diversificar riesgo y proyectarse a los mercados globales.

\section{Conclusiones}

Una vez finalizado este breve panorama del Sector Cafetero Colombiano, partiendo de sus antecedentes históricos, analizando la crisis mundial cafetera de finales del siglo XX, y centrándonos en el nuevo modelo de comercialización implementado en Colombia por la Federación Nacional de Cafeteros, es importante resaltar que los aspectos determinantes del futuro son diversos y que Colombia ha encontrado caminos que lahacen depender de símisma para enfrentar con éxito la volatilidad internacional para este importante sector de la economía colombiana.

Inicialmente es de destacar el papel de la institucionalidad cafetera en el sector, la figura de la Federación y su interacción con los pequeños cultivadores a través de las cooperativas y comités departamentales en las diferentes regiones, además de ser un apoyo importante para la ejecución de estrategias encaminadas a hacer sostenible tanto financiera como técnicamente el cultivo y la explotación del grano, se ha convertido en un verdadero ejemplo de asociatividad. Muy probablemente sin la existencia de un esquema tan fuerte y consolidado como este, los pequeños productores no habrían podido superar las diferentes caídas de los precios intemacionales, ni acceder a buenas prácticas de cultivo y postcosecha.
El modelo comercial que surge en la actualidad como una propuesta importante en la diversificación de productos con mayor participación en la cadena de valor, es fruto del trabajo de varias décadas, no solo desde el posicionamiento de marca y las inversiones publicitarias, sino del trabajo de consolidación de un producto de excelente calidad reconocido por todos los consumidores del mundo. Es gracias a este trabajo previo que un modelo "agroindustrial" como el planteado en la actualidad puede tener participaciones de mercado significativas y con un alto potencial como las logradas en estos primeros años de trabajo.

Ahora bien, la comercialización de productos de valor agregado y diferenciación no son en este momento y seguramente tampoco lo serán en el corto o mediano plazo un aporte significativo al negocio del café en Colombia; la superación de la crisis enfrentada durante la última década del siglo XX no está dada por la diversificación del productoy, por el contrario, es el aumento de los precios internacionales y el contar con un buen manejo de inventarios de café verde, así como la profunda reestructuración de la Federación Nacional de Cafeteros y las nuevas políticas de manejo de la 
institucionalidad cafetera, los que permitirán resurgir al sector. Sin embargo las nuevas propuestas comerciales son una medida a futuro, una salida que podríamos asociar con una reconversión del sector que espera concretar su éxito comercial sobre el trabajo que durante más de cien años han desarrollado miles de pequeños cultivadores a lo largo y ancho de la geografía colombiana cultivando el mejor café del mundo.
Por último, es fundamental resaltar que el ejemplo del sector cafetero -cuyo cambio fue en gran medida propiciado por variaciones en el entorno internacional- es un ejemplo digno de seguir por otros sectores, especialmente de la agroindustria. Solo en la medida en que comprendamos que el camino del valor agregado genera posibilidades reales de progreso, se podrá llegar a los mercados internacionales con propuestas valiosas para los consumidores del mundo entero.

\section{Bibliografía}

BANCO MUNDIAL (2002). Estudio del sector Cafetero en Colombia. Informe 24600-CO.

CAFÉ DE COLOMBIA. http://www.cafedecolombia.com/comercializacion/denominaci onorigen/denominacion1.html.

CHALARCA, José (1998). Vida y Hechos del Café en Colombia. Presencia Editores, Bogotá.

EL COLOMBIANO .Holding Cafetera Procafecol, para agregarle valor al café.

FEDERACIÓN NACIONAL DE CAFETEROS DE COLOMBIA (2005). Informe del Gerente General LXV Congreso Nacional de Cafeteros. Bogotá.

OCAMPO, José Antonio (1989). Los Orígenes de la Industria Cafetera, 1830-1929. Bogotá, Planeta.

OCAMPO, José Antonio (1997). La Federación y el Modelo Cafetero Colombiano, ejemplos sobresalientes en el mundo del café.

OXFAM INTERNACIONAL (2002). Nuestro año 2002.

PERFETTI, Mauricio et al. Cuantificación de los impactos Micro-Económicos y sociales de la crisis cafetera en Colombia. Centro de Estudios Regionales, Cafeteros y empresariales CRECE.

PIZANO, Diego (2001). El Café en la Encrucijada. Alfaomega.

REVISTA DINERO (2001). Café: la última gota. Edición 137, Julio 19.

REVISTA JAVERIANA (2003). El Sector Cafetero, Crisis y medidas para su recuperación. Junio. Bogotá. Universidad Javeriana.

REVISTA SEMANA (2002). Café sombrío. Edición 970, Diciembre. Bogotá.

SILVA, Gabriel (2003). El Sector Cafetero Crisis y Medidas para su Recuperación. Revista Javeriana. Junio.

SILVA, Gabriel. El amanecer de una nueva era. 